\title{
EDITORIAL
}

For reprint orders, please contact: reprints@futuremedicine.com

\section{DSM-5 internet gaming disorder needs a unified approach to assessment}

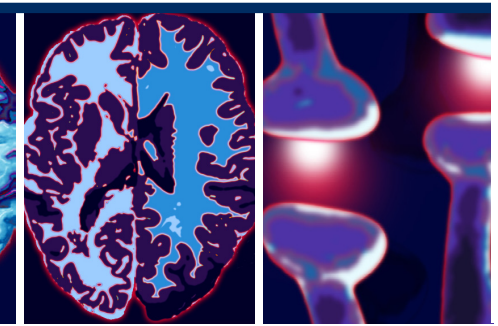

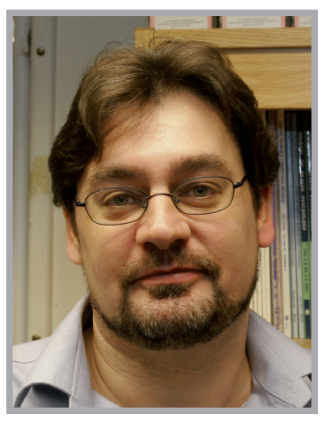

Mark D Griffiths*1

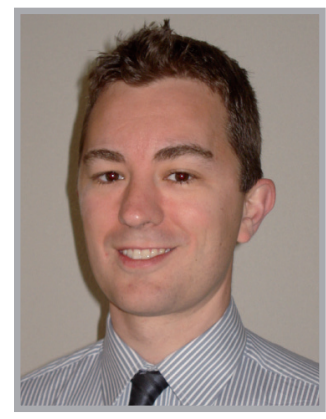

Daniel L King²

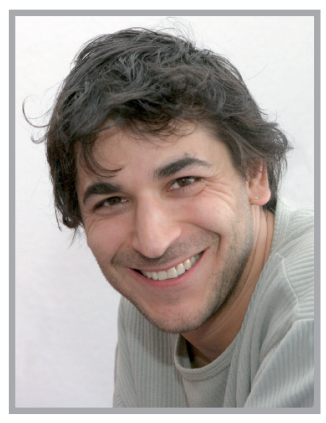

Zsolt Demetrovics ${ }^{3}$
Over the last 15 years, research into various online addictions has greatly increased [1]. Prior to the publication of the latest DSM-5 by the American Psychiatric Association [2], there had been some debate as to whether 'internet addiction' should be introduced into the text as a separate disorder [3,4]. Alongside this, there has also been debate as to whether those researching in the online addiction field should be researching generalized internet use and/or the potentially addictive activities that can be engaged on the internet (e.g., gambling, video gaming, sex and shopping) [5]. Following these debates, the Substance Use Disorder Work Group recommended that the DSM-5 include a subtype of problematic internet use (i.e., internet gaming disorder [IGD]) in the 'Emerging Measures and Models' section as an area that needed future research before being included in future editions of the DSM [4]. According to Petry and O'Brien, IGD will not be included as a separate mental disorder until the defining features of IGD have been identified, reliability and validity of specific IGD criteria have been obtained cross-culturally, prevalence rates have been determined in representative epidemiological samples across the world, and etiology and associated biological features have been evaluated [4].

Although there is now a rapidly growing literature on pathological video gaming [6], one of the key reasons that IGD was not included in the main text of the DSM-5 was that the Substance Use Disorder Work Group concluded that no standard diagnostic criteria were used to assess gaming addiction across these many studies. A recent review of instruments assessing problematic, pathological and/or addictive gaming by King and colleagues reported that 18 different screening instruments had been developed, and that these had been used in “...the Substance Use Disorder Work Group recommended that the DSM-5 include a subtype of problematic internet use ... in the 'Emerging Measures and Models' section as an area that needed future research..."

'International Gaming Research Unit, Psychology Division, Nottingham Trent University, Burton Street, Nottingham, NG1 4BU, UK

${ }^{2}$ School of Psychology, University of Adelaide, Adelaide, Australia

${ }^{3}$ Institute of Psychology, Eötvös Loránd University, Budapest, Hungary

*Author for correspondence: mark.griffiths@ntu.ac.uk 
"Video gaming that is problematic, pathological and/or addictive ... lacks

a widely accepted definition."
63 quantitative studies comprising 58,415 participants [7]. This comprehensive review identified both strengths and weaknesses of these instruments.

The main strengths of the instrumentation included the: brevity and ease of scoring; excellent psychometric properties, such as convergent validity and internal consistency; and robust data that will aid the development of standardized norms for adolescent populations. However, the main weaknesses identified in the instrumentation included: core addiction indicators being inconsistent across studies; a general lack of any temporal dimension; inconsistent cutoff scores relating to clinical status; poor and/or inadequate inter-rater reliability and predictive validity; and inconsistent and/or dimensionality. It has also been noted by a number of authors that the criteria for IGD assessment tools are theoretically based on a variety of different potentially problematic activities, including substance use disorders, pathological gambling and/or other behavioral addiction criteria [4,7]. There are also issues surrounding the settings in which diagnostic screens are used, since those used in clinical practice settings may require a different emphasis that those used in epidemiological, experimental and neurobiological research settings $[7,8]$.

Video gaming that is problematic, pathological and/or addictive (i.e., IGD) lacks a widely accepted definition. In a recent review, Pápay and colleagues argued that some researchers consider video games as the starting point for examining the characteristics of this specific disorder, while others consider the internet as the main platform that unites different addictive internet activities, including online games [9]. Recent studies have made an effort to integrate both approaches [10,11]. Consequently, IGD can either be viewed as a specific type of video game addiction, as a variant of internet addiction or as an independent diagnosis.

Griffiths has argued that although all addictions have particular and idiosyncratic characteristics, they share more commonalities than differences (i.e., salience, mood modification, tolerance, withdrawal symptoms, conflict and relapse), and this probably reflects a common etiology of addictive behavior [12]. Consequently, online game addiction may be viewed as a specific type of video game addiction. Similarly, Porter and colleagues do not differentiate between problematic video game use and problematic online game use [13]. They conceptualized problematic video game use as excessive use of one or more video games resulting in a preoccupation with and a loss of control over playing video games, and various negative psychosocial and/or physical consequences. However, unlike Griffiths, their criteria for problematic video game use does not include other features usually associated with dependence or addiction, (e.g., tolerance and physical symptoms of withdrawal), as they mention there is no clear evidence that problematic gaming is associated with such phenomena [12]. Researchers, such as Young, view online gaming addiction as a subtype of internet addiction and that the internet itself provides situation-specific characteristics, which facilitate gaming becoming problematic and/or addictive [14].

Kim and Kim's problematic online game use model takes a more integrative approach and claims that neither of the approaches outlined above adequately capture the unique features of online games, such as massively multiplayer online role-playing games (MMORPGs) [11]. They argue that the internet is just one channel where people may access the content they want (e.g., gambling, shopping and sex) and that such users may become addicted to the particular content rather than the channel itself. This is analogous to the argument by Griffiths that there is a fundamental difference between addiction to the internet and addictions on the internet [5]. However, MMORPGs differ from traditional standalone video games as there are social and/or role-playing dimensions that allow interaction with other gamers [15].

The problematic online game use model resulted in five underlying dimensions of addictive gameplay (i.e., euphoria, health problems, conflict, failure of self-control and preference of virtual relationship). Demetrovics and colleagues also support the integrative approach, and stress the need to include all types of online games in addiction models in order to make comparisons between genres and gamer populations possible (e.g., those who play online real-time strategy games and online first-person shooter games, in addition to the widely researched MMORPG players). Their model comprises six dimensions (i.e., preoccupation, overuse, immersion, social isolation, interpersonal conflicts and withdrawal) [10]. 
Irrespective of approach or model, the components and dimensions that comprise online gaming addiction outlined above are very similar to the IGD criteria in the 'Emerging Measures and Models' section of the DSM-5. For a person to be diagnosed as having IGD, five or more criteria need to be endorsed and resulting in clinically significant impairment [12]. More specifically: preoccupation with internet games (salience); withdrawal symptoms when internet gaming is taken away (withdrawal); the need to spend increasing amounts of time engaged in internet gaming (tolerance); unsuccessful attempts to control participation in internet gaming (relapse/loss of control); loss of interest in hobbies and entertainment as a result of, and with the exception of, internet gaming (conflict); continued excessive use of internet games despite knowledge of psychosocial problems (conflict); deception of family members, therapists or others regarding the amount of internet gaming (conflict); use of the internet gaming to escape or relieve a negative mood (mood modification); and loss of a significant relationship, job, or educational or career opportunity because of participation in internet games (conflict).

The fact that IGD was included in the 'Emerging Measures and Models' section of the DSM-5 appears to have been well received by researchers and clinicians in the gaming addiction field (and by those individuals that have sought treatment for such disorders and had their experiences psychiatrically validated and feel less stigmatized). However, for IGD to be included in the section on 'SubstanceRelated and Addictive Disorders' along with 'Gambling Disorder', the gaming addiction field must unite and start using the same assessment measures so that comparisons can be made across different demographic groups and different cultures. For epidemiological purposes, Koronczai and colleagues asserted that the most appropriate measures in assessing problematic online use (including internet gaming) should meet six requirements [8]. Such an instrument should have: brevity (to make surveys as short as possible and help overcome question fatigue); comprehensiveness (to examine all core aspects of IGD as possible); reliability and validity across age groups (e.g., adolescents vs adults); reliability and validity across data collection methods (e.g., online, face-to-face interviews, and paper-and-pencil); cross-cultural reliability and validity; and clinical validation. It was also noted that an ideal assessment instrument should serve as the basis for defining adequate cutoff scores in terms of both specificity and sensitivity. To fulfill all these requirements, future research should adjust the currently used assessment tools to the newly accepted DSM-5 criteria and make more effort to reach and study clinical samples, which is an unequivocal shortcoming of both internet and gaming research $[16,17]$.

In addition to further epidemiological and clinical research, further research is also needed on the neurobiology of IGD. A recent systematic review of 18 neuroimaging studies examining internet addiction and IGD by Kuss and Griffiths noted that: "These studies provide compelling evidence for the similarities between different types of addictions, notably substance-related addictions and internet and gaming addiction, on a variety of levels. On the molecular level, internet addiction is characterized by an overall reward deficiency that entails decreased dopaminergic activity. On the level of neural circuitry, internet and gaming addiction lead to neuroadaptation and structural changes that occur as a consequence of prolonged increased activity in brain areas associated with addiction. On a behavioral level, internet and gaming addicts appear to be constricted with regards to their cognitive functioning in various domains" [18].

The good news is that research in the gaming addiction field does appear to be reaching an emerging consensus. King and colleagues noted that across many different studies, IGD is commonly defined by withdrawal, loss of control and conflict. However, it is critical that a unified approach to the assessment of IGD is developed as this is the only way that there will be a strong empirical basis for IGD to be included in the next DSM [7].

\section{Financial \& competing interests disclosure}

The authors have no relevant affliations or financial involvement with any organization or entity with a financial interest in or financial conflict with the subject matter or materials discussed in the manuscript. This includes employment, consultancies, honoraria, stock ownership or options, expert testimony, grants or patents received or pending, or royalties.

No writing assistance was utilized in the production of this manuscript.

"...internet gaming
disorder is commonly
defined by withdrawal,
loss of control and
conflict."




\section{References}

1 Kuss DJ, Griffiths MD, Karila L, Billieux J. Internet addiction: a systematic review of epidemiological research for the last decade. Curr. Pharm. Des. doi:10.2174/138161281131 99990617 (2013) (Epub ahead of print).

2 American Psychiatric Association. Diagnostic and Statistical Manual of Mental

Disorders - Text Revision (5th Edition).

American Psychiatric Association, DC, USA (2013).

3 Block JJ. Issues for DSM-V: internet addiction. Am. J. Psychiatry 165, 306-307 (2008).

4 Petry NM, O'Brien CP. Internet gaming disorder and the DSM-5. Addiction 108, 1186-1187 (2013).

5 Griffiths MD. Internet addiction - time to be taken seriously? Addict. Res. 8, 413-418 (2000).

6 Griffiths MD, Kuss DJ, King DL. Video game addiction: past, present and future. Curr. Psychiat. Rev. 8, 308-318 (2012).

7 King DL, Haagsma MC, Delfabbro PH, Gradisar MS, Griffiths MD. Toward a consensus definition of pathological video-gaming: a systematic review of psychometric assessment tools. Clin. Psychol. Rev. 33, 331-342 (2013)

8 Koronczai B, Urban R, Kokonyei G et al. Confirmation of the three-factor model of problematic internet use on off-line adolescent and adult samples. Cyberpsychol. Behav. Soc. Netw. 14, 657-664 (2011).

9 Pápay O, Nagygyörgy K, Griffiths MD, Demetrovics Z. Problematic online gaming. In: Behavioral Addictions: Criteria, Evidence and Treatment. Rosenberg K, Feder L (Eds). Elsevier, NY, USA (In Press).

10 Demetrovics Z, Urbán R, Nagygyörgy K et al. The development of the Problematic Online Gaming Questionnaire (POGQ). PLoS One 7(5), e36417 (2012).

11 Kim MG, Kim J. Cross-validation of reliability, convergent and discriminant validity for the problematic online game use scale. Comput. Hum. Behav. 26, 389-398 (2010).

12 Griffiths MD. A 'components' model of addiction within a biopsychosocial framework. J. Subst. Use 10, 191-197 (2005).
13 Porter G, Starcevic V, Berle D, Fenech P. Recognizing problem video game use. Aust. NZ J. Psychiatry 44, 120-128 (2010).

14 Young KS. Internet addiction: the emergence of a new clinical disorder. Cyberpsychol. Behav. 1, 237-244 (1998).

15 Allison SE, von Wahlde L, Shockley T, Gabbard GO. The development of the self in the era of the internet and role-playing fantasy games. Am. J. Psychiatry 163, 381-385 (2006).

16 King DL, Delfabbro PH, Griffiths MD, Gradisar M. Assessing clinical trials of internet addiction treatment: a systematic review and CONSORT evaluation. Clin. Psychol. Rev. 31, 1110-1116 (2011).

17 King DL, Delfabbro PH, Griffiths MD. Cognitive-behavioral approaches to outpatient treatment of internet addiction in children and adolescents. J. Clin. Psychol. 68, 1185-1195 (2012).

18 Kuss DJ, Griffiths MD. Internet and gaming addiction: a systematic literature review of neuroimaging studies. Brain Sci. 2, 347-374 (2012). 